Hypoxic air machines

\section{Hypoxic air machines: performance enhancement through effective training-or cheating?}

\section{Spriggs}

Following an investigation of the football clubs using hypoxic air machines, the Australian Football League (AFL) has decided not to ban the machines. This seems, however, to be a reluctant decision since it appears that some AFL officials still feel there is something undesirable about the use of the machines. Use of the machines raises questions about performance enhancement and the role of technology. It prompts consideration of the grounds for banning performance enhancing devices or substances and raises questions about what constitutes a drug

A machine being used by Australian footballers, which is designed to imitate the effects of high altitude training and enhance performance has prompted an investigation by the Australian Football League (AFL) and sparked debate in the media. The AFL decided not to ban the machine but a sense of unease about its use remains and there seems to be some difficulty in articulating the cause of that unease. The league's medical officers say the hypoxicators do not contravene their antidoping code or the league's rules, ${ }^{1}{ }^{2}$ but according to at least one AFL official, the use of the machines is "sending the wrong message concerning the image of our game".

The hypoxic air machine provides nitrogen rich air which is thought to boost the oxygen carrying capacity of the blood, which in turn boosts the production of red blood cells-in much the same way as the banned drug erythropoietin (EPO). ${ }^{3}{ }^{4}$ There is a lack of scientific evidence to support the comparison with EPO but the comparison is troubling for some. Others are concerned about the fact that the machine provides an artificial aid to athletes. According to one AFL medical commission member: "It is the sort of thing, which makes you a little bit uncomfortable, because it is trying to use an artificial means to gain an advantage in a contest where you really want man against man". ${ }^{5}$

Abbreviations: AFL, Australian Football League; AIS, Australian Institute of Sport; EPO, Erythropoietin
Many in the sports science community are sceptical of the supposed benefits and reject worries about hypoxic air machines being an artificial aid. ${ }^{6} \mathrm{~A}$ study conducted at the Australian Institute of Sport (AIS) found that hypoxic devices produce on average, an 0.8 per cent improvement in endurance-the same as could be achieved by swallowing a placebo. ${ }^{5}$ One AFL club doctor argues that it would be "a lot cheaper to give them a Smartie". ${ }^{3}$ Professor Allan Hahn, head of physiology at the Australian Institute of Sport dismisses as "illogical" the argument that hypoxic air machines should be banned. Banning them because they provide an "artificial environment" would mean also banning heat chambers and weight training facilities. ${ }^{5}$ Furthermore, altitude or hypoxic training is "widespread" in sport. Most endurance athletes at the Victorian Institute of Sport undertake some sort of altitude training as part of their training programme. The athletes sleep in altitude tents and train at sea level in order to improve performance. ${ }^{7}$ The chief executive of Port Adelaide defends use of the machine by asking if the AFL would be concerned if he trained the squad at a higher altitude. $^{8}$

Brisbane player Jason Akermanis who owns and has been using the hypoxicator since 1999 is adamant that use of the machine does not amount to cheating": "Exercise is performance enhancing, eating the right diet is performance enhancing". And, he added: the AFL "can't take away someone's right to breathe". 6

Arguments in support of the machine suggest that enhancement by itself is not a problem. Some forms of performance enhancement in sport are accepted and some are considered cheating. In particular, an advantage gained chemically rather than by training is considered improper because it is viewed as a "biomedical short cut" that diminishes the value of the achievement. ${ }^{9}$ It Is not clear however, into which category the hypoxic air machine really falls. Defenders of the machine argue that it merely reproduces a high altitude training environment. Training is still necessary but it becomes more effective. Paradoxically, the appeal of the machine is that it is thought to boost the oxygen carrying capacity of the blood and the production of red blood cells-this suggests it offers a chemical improvement to performance.

The argument that hypoxic air machines should not be used because they constitute a form of technology that enhances performance by artificial means, is complicated by the news that another AFL club, which is undertaking hypoxic training to build endurance, does this without the use of technology. The Sydney Swans swim laps holding their breath and this is said to have a similar effect to that achieved with the hypoxicator.

The interesting thing that comes out of the debate about hypoxic air machines and whether they should be banned, is that there is nothing wrong with performance enhancement in itself. It is also evident that a distinction between natural and artificial means to gain an advantage is neither clear cut nor morally significant. There do not seem to be any risks associated with using the machines, and given that the decision to use it is voluntary, the only remaining justification for banning the machine would be on grounds of fairness-specifically in relation to fair rules of competition.

J Med Ethics 2005;31:112-113.

doi: 10.1136/jme.2003.005280

Correspondence to: M Spriggs, Ethics Unit, Murdoch Childrens Research Institute, Royal Childrens Hospital, Parkville, Victoria, 3052, Australia; Centre for the Study of Health and Society, University of Melbourne, Australia; Centre for Human Bioethics, Monash University, Australia; merle.spriggs@mcn.edu.au

\section{REFERENCES}

1 Rucci M. League clears air over device. The Advertiser, 2003 May 23;sport section, 94.

2 Halloran J. It's the finals or burst for these hypoxicating Swans. Sydney Morning Herald, 2003 May 23;news section, 1.

3 Bernard G. Docs doubt air fair. Herald Sun, 2003 May 16;sports section: $117,120$.

4 Le Grand C. Bad air day-altitude simulator investigation. The Weekend Australian, 2003 May 17; sport section, 47 
5 Le Grand C, Cochlan S. AFL probe fails to clear the air. The Australian, 2003 May 16;sport section, 31

6 Rielly S. Bombers query benefit of machine. The Age, 2003 May 16;sport section, 14.
7 Ainley $M$. Elite athletes prefer altitude tents. Herald Sun, 2003 May 16;sports section, 116.

8 Cartwright D, Rucci M. Lions Power defend tactic. Herald Sun, 2003 May 16;sports section, 116.
9 Juengst ET. What does enhancement mean? In: Parens E, ed. Enhancing human traits: ethical and social implications. Washington, DC:

Georgetown University Press, 1998:39.

Hypoxic air machines

\section{Commentary}

\section{T Tännsjö}

$\mathrm{T}$ resort to hypoxic air machineswould that be to cheat? This clearly depends on whether such machines are prohibited or not. So the important question is this: Should sport authorities prohibit them or not?

One way of approaching this question may be to argue casuistically. Erythropoietin (EPO) is prohibited. Blood doping is prohibited. Training at high altitude is allowed. Does the hypoxic air machine bear more resemblance to training at high altitude than to the use of EPO? If that is the case it should not be prohibited. If, on the other hand, it bears more resemblance to the use of EPO, then it should be prohibited.

However, to argue casuistically is not entirely satisfactory. Even if, through such reasoning, we reach an answer, we do not obtain a principled explanation of the answer. We may get a hint at what to do (allow or prohibit), but not at why we should do so. ${ }^{1}$ So the question need to be posed at a more principled level: If rules against doping in sport are to be adopted, with reference to what kind of notion of fair play or justice should they be defended?

It seems to be part of the ethos of sport that the winner of the genetic lottery, the person who, genetically speaking, is most fit, should also be the winner of the competition. This (Nietzschean) notion of justice or fairness is very different from, and even opposite to, the (more civilised) one we rely on in other contexts. In most other situations we claim that people should not be praised for their natural endowments, since they are not responsible for them. If a person is less talented, naturally, than another person, we should allow that he or she uses medical means to catch up with the more talented person. If this is not possible, the less talented person should be compensated, rather than punished, for their relative deficiency. This is not so in elitist sport. Here we want those who are naturally most talented to prevail.

On this notion of justice, even training was once looked upon with suspicion in sport. In particular, scientific full time training was conceived of as a way of giving an unfair advantage to those who resorted to it, such as the East German swimmers. Such methods allowed these swimmers to prevail over more talented competitors from other countries. However, it soon transpired that there was no way of containing training. The solution was to allow it, with the understanding that all who competed in elitist sport would resort to it. So no unfair advantage remained.

The situation with performance enhancing drugs, not to speak of genetic enhancement, is very different. Obviously, the use of performance enhancing drugs may mean that those who are genetically speaking less well equipped will catch up with those who are better equipped. And according to the existing ethos of sport, this is not fair.

A much publicised example of this is of the Finnish cross country skier Eero Mäntyranta. Throughout his career in the 1960s Mäntyranta was suspected of blood doping because his red blood count was $20 \%$ higher than that of other athletes. Thirty years later, scientists tested 200 members of his family and discovered that 50 of them, including Mäntyranta himself, were born with a rare genetic mutation that causes an increase in oxygen-rich red blood cells. This mutation made Mäntyranta almost invincible in the heyday of his career.
Today his less generously genetically endowed competitors could, in order to catch up with him, resort to EPO. Many people would think that this was being unfair. This kind of sentiment may explain why the resistance to doping is more recalcitrant than the opposition ever was to training, or even to systematic training.

If this rough sketch of the ethos of sport is correct, what are we to say, with reference to it, about the hypoxic air machine? To the extent that the use of the machine does not level out genetic, inborn differences between competitors, there is no reason to prohibit it. To the extent that it can be used even by Mäntyranta, to increase his capacity for oxygen intake even more, it poses no problem to the ethos of sport. We may treat it as training-training at high altitude or the use of altitude tents.

However, what if it had been different? What if the hypoxic air machine was a means to level out natural, inborn differences? Well, then we would have had to face a choice: to ban the machine or change the ethos of sport.

This is not the place to go deep into this discussion. Allow me only, since this is a question we have to face anyway, to indicate my favoured choice. My suggestion is that, rather than sticking to the existing ethos of sport, we should change it. Even in sport we should allow that people level out their inborn differences. We should allow all sorts of (safe) medical and genetic methods of enhancement of athletes. This would pave the way for more exciting competitions and for the possibility that anyone who wants to do so can take part in them on equal terms. And at last we would come to grips with the problem of elitism in sport. ${ }^{2}$

$J$ Med Ethics 2005;31:113.

doi: 10.1136/jme.2003.005355

Correspondence to: T Tännsjö, Department of Philosophy, Stockholm University, 10691 Stockholm, Sweden; torbjorn.tannsjo@ philosophy.su.se

\section{REFERENCES}

1 Tännsjö T. Understanding Ethics. Edinburgh: Edinburgh University Press, 2002, Chapter 9.

$2 \mathrm{Cf}$, my chapter on elitism in sport in Tännsjö $\mathrm{T}$, Tamburrini CM, eds. Values in Sport. London: Routledge, 2000 
Hypoxic air machines

\section{Commentary}

\section{Tamburrini}

M any elite athletes try to imitate the effects of high altitude training by using hypoxic air machines. These training devices are thought to boost the oxygen carrying capacity of the blood and the production of red blood cells which are believed to yield an important competitive advantage in endurance sports. Hypoxic air machines do not contravene current antidoping regulations. However, many sports practitioners and some officials have expressed a feeling of uneasiness towards this new training technique, comparing it with traditional doping. And, indeed, the introduction of hypoxic air machines paves the way for allowing doping in a near future.

All sports related arguments that have been advanced in defence of these machines also support traditional doping. For instance, some objectors argue that hypoxic air machines render "a chemical advantage" and should therefore be forbidden. A standard defence against this criticism is that "even if it becomes more effective, training is still necessary for users of hypoxic air machines". The same answer, however, could be given by supporters of lifting the prohibition on doping. In a sense, every training technique (including doping) yields a chemical process in the body.

Consider now fairness in competition. Some athletes will be able to rest in oxygen tents, other will not. Those in favour of hypoxic air machines will probably answer that sport competitions are essentially unfair, in the sense that nature has endowed different athletes with different sporting abilities. Hypoxic air machines simply add a further element of inequality between competitors that could even yield an equalising effect (for instance, when a genetically inferior athlete gets the possibility of using an oxygen tent). In my opinion, this argument neutralises the objection of unfairness of hypoxic air machines. But, again, this defence opens the way for traditional doping: chemical substances might also have an equalising effect when administered to the less endowed athletes. ${ }^{1}$

Many people still feel that if we let an athlete who trained with an hypoxic air machine win a competition, its outcome will then be decided by factors other than physical excellence and the spirit of competiton. These machines, therefore, violate the ideal of a sport competition, at least as these objectors conceive of it.

This is, in my view, an amazing objection. In the 1960s, the Finnish cross country skier Eero Mäntyranta was suspected of blood doping because his red blood count was 20\% higher than of his competitors. Thirty years later, 200 members of his family were tested by scientists, and they found that 50 of them, including Mäntyranta himself, were born with a rare genetic mutation that causes an increase in oxygen-rich red blood cells. This mutation gave Mäntyranta a competitive advantage over his rivals. Now, why would it have been unfair, or contrary to the ideal of sport, to give Mäntyranta's competitors the chance of equalising competitive conditions by resorting to old fashioned blood doping or, if they had been available at that time, hypoxic air machines? (Or, for that matter, to genetic enhancements in a not so far ahead future? $)^{2}$

Many people think such training tactics are obviously unacceptable and tend to cling to the idea that only natural talent should decide the outcome of a sport competition. But why should congenital, genetically determined traits lead to victory and praise and not acquired ones? Such a notion of justice is not only flawed, it is also becoming obsolete due to the rapid medical developments that we are experiencing today. There is no reason to let the genetic lottery decide the outcome of a sport competition, when the odds of winning of all competitors might be levelled out by intentional and goal-oriented efforts to achieve higher levels of sporting performance.

Are critics right then when they oppose hypoxic air machines on the grounds of their resemblance with doping? Not entirely. It could be argued that there actually is a powerful case for allowing hypoxic air machines, while still banning traditional doping, which rests not on sports related but instead on medical reasons; such as the fact that there do not seem to be any health risks associated with their use. (See, for instance, Merle Spriggs' article. ${ }^{3}$ )

I find this position difficult to substantiate. Not only does the health argument deny autonomy to people as regards the right to decide how many risks they are willing to take to achieve professional success and rewards, but also in the end the medical objection will also prove toothless as new genetic technologies will make it possible to enhance sporting performance without risk of serious health injuries. Even sceptics nowadays recognise that the new genetic technologies have the potential of preventing and curing serious diseases. Therefore, and unlike traditional doping techniques, genetic technology will be widely used (as a matter of fact, it is already being used) in general medicine. Thus, before the new techniques are introduced in other areas of society, for instance sports medicine and education, they will be tested and developed in the healthcare system. Although still involving some risks, following their medical application, genetic modification techniques will most probably become as harmless as any medical technique can be-at least, no more harmful than current elite training methods.

Thus, the perception of critics that hypoxic air machines weaken current restrictions on the use of substances and methods that enhance performance in elite sports is correct. The conclusion they draw from this, however, is wrong: both hypoxic air machines and doping should be allowed.

Once the sports related arguments against doping are neutralised by widespread use of hypoxic air machines, progress in genetic engineering will also render the medical objections against doping obsolete. We should welcome, rather than fear, this effect. By exposing the arbitrariness of the ban on doping, hypoxic air machines contribute to more open and transparent sport competitions in the future.

J Med Ethics 2005;31:114. doi: 10.1136/jme.2003.005363

Correspondence to: C Tamburrini, claudio. tamburrini@mailbox.swipnet.se

\section{REFERENCES}

1 Tamburrini CM. What's wrong with doping? In: Tännsjö T, Tamburrini CM, eds. Values in sportelitism, nationalism, gender equality and the scientific manufacture of winnners. London: E \& FN Spon (Routledge), March, 2000.

2 Tännsjö T, Tamburrini CM, eds. The Genetic Design of Winness. London; Routledge (forth coming).

3 Merle $\mathbf{S}$. Hypoxic air machines: performance enhancement through effective training-or cheating? J Med Ethics 2005;31:112. 
Hypoxic air machines

\section{Commentary}

\section{P Fricker}

$\mathrm{T}$ he debate on hypoxic air devices is of interest to me as a doctor, a researcher, and an active participant in a number of committees and bodies which are concerned with ethics and doping. I write this commentary as a personal contributor though, and not as a representative of any particular organisation or authority.

The issues here appear to revolve around the concept of cheating in order to gain an unfair advantage in a sporting contest. The use of artificial means to enhance performance immediately raises eyebrows because of an unease about using other than "natural" (dare I say "God given"?) talents to compete (and win) at sport. There is a perception that cheating implies anything that appears to enhance performance by nonnatural physical or chemical means. This seems fine at first pass but on a second look the issue is not so clear.

Modern sport at the elite level is all about the limits of physiology. Athletes now spend their daily lives doing nothing but enhancing their performances. Over the years athletes have moved on from simply repeating their particular sport techniques in training and now incorporate cross training, strength and conditioning work, nutrition, recovery practices, and psychological techniques to maximise performance in competition.
With advanced understanding of the chemistry and physics of the body, and of the effects of training under different climatic and environmental conditions, newer techniques such as altitude training have been devised and put into practice. Altitude was thought to provide the natural stimulus to enhanced oxygen carrying capacity and as a result of this, altitude houses and hypoxic breathing devices were born. As it happens, it may not be oxygen carrying capacity that works here, but better biological buffering systems which facilitate tolerance of hard efforts.

So where does the cheating come in? The definition of cheating (and we could say doping in this context) for me is centred around a couple of principles which I think provide useful direction for decision making.

The first of these is the notion of abusing our own physiology and anatomy to maximise performance. In other words, deliberately manipulating the body by some non-natural intervention is wrong. Surgery to improve flexibility beyond a normal range, or injection of some substance which abnormally accelerates a physiological process or exceeds a physiological normal is intuitively wrong. The idea of becoming "supernormal" is the key here.

The risk to health is also important. It would be wrong to accept the risk of impairing health to gain an advantage in sport, which is what happens when anabolic steroids are abused. Large doses to improve power and speed cost the user in terms of permanent changes to many systems within the body, and many of these changes are definitely detrimental to health.

Conversely, the use of physical or chemical means to maximise performance through normal physiological adaptation is not cheating. The argument that "if it does not occur in nature it must be wrong" does not stand up to scrutiny. As stated in the article, to throw out any such means would be illogical because this would mean the prohibition of heat chambers (for acclimatisation to hot and possibly humid conditions), weight training rooms, bicycles, treadmills, rowing machines, and swimming pools with chlorinated heated water in air conditioned facilities. Training with such facilities does not provide any performance advantage over what might be gained by any athlete who runs outside, swims in a lake and lifts heavy rocks-but these facilities make such training adaptations more easily available. This is not wrong.

Similarly, the use of hypoxic devices, altitude tents, and altitude chambers all mimic environmental conditions which promote adaptations and (may) enhance performance. They do not take the athlete into the supernormal range, and as long as the practices are safe, they pose no ethical problem.

$J$ Med Ethics 2005;31:115. doi: 10.1136/jme.2004.005470

Correspondence to: Professor P Fricker, Australian Institute of Sport, PO box 176, Belconnen, Canberra, ACT, Australia 2616; peter.fricker@ausport.gov.au 